\title{
A Numerical Study on Water Wetting Associated With the Internal Corrosion of Oil Pipelines
}

\author{
Hassan Pouraria ${ }^{a, b}$, Jung Kwan Seo ${ }^{\text {b }}$ Jeom Kee Paik ${ }^{a, b, c, *}$ \\ ${ }^{\text {a }}$ Department of Naval Architecture and Ocean Engineering, Pusan National University, Busan 609-735, Republic of Korea \\ b The Korea Ship and Offshore Research Institute (The Lloyd's Register Foundation Research Centre of Excellence), \\ Pusan National University, Busan 609-735, Republic of Korea \\ ${ }^{c}$ Department of Mechanical Engineering, University College London, Torrington Place, London WC1E 7JE, UK
}

\begin{abstract}
Highlights:
1: A refined CFD model is employed to predict the type of wetting in flowlines with reasonable accuracy.

2: As the diameter of pipe increases the probability of water wetting and corrosion risk increases.

3: As the viscosity of oil increases the likelihood of water wetting and corrosion risk decreases.

4: A decrease in oil-water interfacial tension results in a decrease in corrosion risk.

5: The higher the density of oil the less the likelihood of water wetting and corrosion.
\end{abstract}

\begin{abstract}
Long distance pipelines are considered as the vein of the oil and gas industry on land and offshore. A well often produces water along with crude oil. The presence of water as well as dissolved gases such as $\mathrm{CO}_{2}$ and $\mathrm{H}_{2} \mathrm{~S}$ introduces a serious menace of internal corrosion. It is well known that the distribution of water and oil inside the pipeline has a great influence on the corrosion rate. As a matter of fact, internal corrosion occurs when a free layer of water comes in contact with the pipe. Hence, predicting the distribution of water inside the pipe and identifying the continuous phase that directly wet the wall is of foremost importance when dealing with internal corrosion of oil pipelines. The accurate prediction of the distribution of water significantly increases the accuracy of corrosion prediction as well as the confidence regarding the integrity of the pipelines. In spite of all the great efforts toward studying different influential factors associated with the internal corrosion of steel pipelines, a large gap of knowledge is observed in predicting the water wetting. The objective of the present study is to employ a tuned two-fluid model by taking advantage of computational fluid dynamics, that is capable of predicting the distribution of water and the type of wetting (water wetting/oil wetting) at the bottom of the pipe. Furthermore, the effect of different parameters such as pipe diameter, oil density, oil viscosity and interfacial tension on the transition from water wetting to oil wetting is studied.
\end{abstract}

\section{Introduction}

The transmission of multi-phase flows from a well to a main platform or onshore processing units is a major concern for offshore developments. An efficient design, considering the known influential factors, could significantly reduce the capital and operational costs. Crude oil is often transmitted simultaneously with water. In the early stages of a well's lifetime the amount of formation water might be negligible. However, mature wells usually produce significant amount of water. Furthermore, water injection is often used in enhanced oil recovery process.

The internal structure of oil-water interface, known as flow pattern, critically depends on the fluid and flow characteristics as well as the geometry of the pipe. Generally, two phase oil-water flows in horizontal pipes are classified into two major groups and several sub groups. At relatively low velocities the gravitational force is dominant which tends to separate oil and water with a clearly defined interface. This flow pattern is sometimes called stratified flow. However, as the velocity of flow increases the turbulence increases, which in turn, tends to mix two phases. As a result, a dispersed region is observed between two phases. By further increase of flow velocity one of the phases will totally lose its continuity and become dispersed in the continuum of another phase. This flow regime is referred to as dispersed flow (Angeli and Hewitt; 2000a, Xu, 2007)

Apart from the fluid and flow characteristics, the volume fraction of water (water cut) is an important factor that determines the type of flow pattern. At high velocities where we expect to see a dispersed flow, the water cut is a 
controlling factor that specifies the continuous phase. For a given oil-water flow there is a critical water cut beyond which the water will become the continuous phase. This critical point is often called phase inversion (Angeli and Hewitt; 2000a, Xu, 2007; Lovick and Angeli, 2004a; Kumara et al., 2009; Yusuf et al., 2012).

The distribution of water in oil-water flow has a significant effect on the corrosion rate which is an important factor in offshore field development. The presence of water as well as dissolved gases such as $\mathrm{CO}_{2}$ and $\mathrm{H}_{2} \mathrm{~S}$ introduces a serious hazard of internal corrosion. Any contact of a continuous layer of this corrosive water with the pipe (water wetting) can potentially result in an internal corrosion. While a direct contact of oil with pipe will not cause corrosion. Hence, when dealing with internal corrosion of pipelines, it is essential to predict whether the water phase is continuous or totally dispersed in a continuous oil phase. An accurate prediction of the distribution of water significantly increases the accuracy of corrosion prediction as well as the confidence regarding the integrity of the pipelines. Whereas, an incorrect prediction of water distribution leads to significant mistakes in predicting the corrosion rate. Moreover, selecting an appropriate type of inhibitor and estimating the required amount of inhibitor and corrosion resistant materials require a prior knowledge of water distribution inside the pipe (Niborg, 2005; Nesic, 2007; Cai et al., 2012; IIman and Kusmono, 2014; Mohd et al., 2015; Papavinasam et al., 2010).

Corrosion accounts for over $25 \%$ of failures experienced in oil and gas industry. Among different kinds of corrosion, sweet corrosion (CO2 corrosion) is the most frequent one (Kermani and Harrop, 1996). During the past decades many works have been focused on studying different factors affecting the sweet corrosion rate (Nesic, 2007; Bockris et al., 1961; Gray et al., 1989a; Gray et al., 1989b; Nesic et al., 2003; Nordsveen et al., 2003; Wang et al., 2004; de Waard et al., 1995). Moreover, different models have been proposed to estimate the corrosion rate (de Waard et al., 1993; Nesic et al., 1995; Mohd and Paik, 2013; NORSOK, 2005). However, in spite of all the advances, predicting corrosion rate and controlling or mitigating its hazardous effects is still a challenging task. Past studies as well as real field experiences revealed that predicting the internal flow behavior is essential not only for developing a reliable predictive corrosion model but also for eliminating or diminishing the hazardous effects of internal corrosion (Nyborg, 2005; NACE SP0208-2008; Nesic, 2012; Wang and Zhang; 2015).

Due to the higher density of water compared to the oil, the probability of water wetting at the bottom of steel pipe is the highest. Sweet corrosion rate in oil-water flow is dependent on the wetted area by corrosive water. Hence, predicting the onset of oil/water wetting as well as water wetted area is crucial. Furthermore, in case of water wetting, the characteristics of free water layer such as its height, velocity and shear stress with wall are some of the key factors that influence the mass transfer between the pipe and the bulk flow (corrosion rate) (Nesic, 2007; Nesic et al., 2005).

Thus far, few researchers tried to develop models for predicting the onset of oil/water wetting. Wicks and Fraser (1975) stated that as the flow velocity increases more water drop entrainments is observed and there is a critical velocity beyond which all the water phase become dispersed in the oil. They concluded that the critical velocity depends on the pipe diameter. Smith (1987) proposed a simple rule for predicting transition from water wetting to oil wetting condition. Based on the measured corrosion rate of field data they suggested that for water cuts up to $20 \%$ and velocities higher than $1 \mathrm{~m} / \mathrm{s}$ oil wetting will be observed at the bottom of pipe. However, the proposed rule of thumb cannot be applied for different conditions other than the operating condition of the used field data. Adams et al. (1993) also suggested a simple rule for estimating the phase wetting at the bottom of pipe. According to their model for water cuts less than $30 \%$ oil wetting is expected. While for water cuts between $30 \%$ and $50 \%$ oil and water may wet the wall alternatively. For water cuts higher than $50 \%$ water wetting is observed irrespective of the pipe diameter, oil property, velocity, etc. However, field experiences contradict these simple rules. The corrosion may occur at water cuts as low as $1 \%$ or may be negligible for water cuts as high as $50 \%$. As a matter of fact, the transition water cut for oil wetting depends on many factors and such simple rules cannot predict the transition points quantitatively (Craig, 1998; Li, 2009). de Waard et al. (2001) implemented an empirical water wetting correction to their original corrosion model. The model is based on the API of the oil. However, the model does not take into account the effects of pipe diameter, the viscosity of oil, surface tension, etc. Several other models have been proposed to determine the minimum flow velocity required for transition to oil wetting. However, none of them consider all the influential parameters such as different oil properties, pipe geometry, surface wettabality and water cut. A brief description of these models can be found in (NACE SP0208-2008).

Wang et al. (2014) experimentally suggested that the corrosion in oil-brine mixtures can be significantly retarded by forming a stable water in oil emulsion. This finding emphasizes the importance of predicting the onset of water in oil dispersion.

Apart from these, a great deal of effort was gone to establish mechanistic models for predicting the transition point between water wetting and oil wetting (Cai et al., 2004; Li et al., 2006; Tang et al., 2007; Kee et al., 2014; Nesic et al., 2005). Based on the theoretical works of Hinze (1955) and Brauner (2001), a mechanistic model was proposed for predicting the transition between stratified and dispersed flow (water wetting and oil wetting). A comprehensive comparison of the model with experimental data obtained by various techniques showed a great advance in predicting phase wetting in a quantitative manner. The extensive experimental studies indicated that full water wetting is only observed when a free water layer with $100 \%$ water fraction flows at the bottom of pipe. 
Furthermore, it was observed that fully oil wetting is pragmatic when the volume fraction of dispersed water at the bottom of pipe is not higher than $40 \%$. While, for water volume fractions between $40 \%$ and $99 \%$ at the bottom of pipe an intermittent wetting was observed in which water and oil may alternatively wet the pipe. The experimental results also revealed that the corrosion rate for intermittent wetting is significantly lower than that in water wetting regime. However, it cannot be neglected like fully oil wetting (Cai et al., 2012; Kee et al., 2016). This mechanistic model has been included in MULTICORP corrosion prediction model. Recently, another mechanistic model has been proposed by (Torres et al., 2016).

A survey of corrosion prediction models that are widely being used in industry indicates that many of them do not take any effect of oil/water wetting into account. Among them NORSOK M-506, Cassandra developed by BP, KSC, Tulsa model and Oli model are notable. While few of them such as Hydrocor developed at Shell and Corplus developed at Total use simple oil wetting models. Furthermore, few corrosion models have been coupled with multiphase flow predictive tools such as OLGA. An overview of water wetting transition models in different corrosion models can be found in (Nyborg, 2010)

Aforementioned background clearly reveals the importance of modeling two-phase oil water flow. In order to enhance the confidence in corrosion prediction more advanced multiphase models need to be adopted along with the corrosion models. Due to the complex nature of oil-water flow all the influential factors affecting the phase distributions inside the pipes should be taken into account and neglecting any of them may result in remarkable mistakes. Hence, using advanced computational fluid dynamics (CFD) models is essential for predicting the main features of two-phase oil-water flows. A proper setting of a CFD model can provide phase distributions and velocity profiles with high resolutions that significantly reduces the uncertainties in corrosion modeling.

In spite of the importance of predicting flow patterns in oil-water flows, numerical studies on this topic have been reported considerably less. Thus far, few researchers tried to model different flow patterns of oil-water flows. Gao et al. (2003) and Al-Yaari et al., (2011) used volume of fluid (VOF) model for modeling the stratified flows. Walvekar et al. (2009), Monzon (2006), Parvini et al. (2010), Hamad et al. (2013) and Pouraria et al (2013) employed Eulerian-Eulerian approach for modeling dispersed oil-water flows. Furthermore, the application of Eulerian-Lagrangian approach for modeling dispersed oil-water flow was reported by Burlutskiy and Turangan (2015). Pouraria et al. (2016) used Eulerian-Eulerian model for predicting different flow patterns in horizontal oilwater flow.

An Eulerian-Eulerian approach is capable of modeling both dispersed and stratified flows. Hence, it can be used for predicting all the flow patterns provided the appropriate closure models regarding the interfacial forces are implemented in the CFD code. These models have been successfully utilized for simulating different flow patterns of gas-liquid and liquid-liquid flows (Yao et al., 2004; Prosperetti and Tryggvason, 2007; Bestion, 2014; Sathe et al., 2010; Yamoah et al., 2015; Pouraria et al., 2016).

The objective of the present study is to use an Eulerian-Eulerian CFD model for predicting the type of wetting inside a horizontal pipeline transmitting two-phase oil-water flow. The main focus of the present study lays on low water cuts, below phase inversion point, where the water may be dispersed or continuous. The capability of the model in predicting the type of flow patterns as well as predicting the onset of oil/water wetting is examined by making a comparison with experimental data. Furthermore, the effect of different parameters such as pipe diameter, oil density, oil viscosity and interfacial tension on the transition from water wetting to oil wetting is studied.

\section{Computational Fluid Dynamics Approach}

\subsection{Governing Equations}

Numerical simulations were carried out using the two-fluid Eulerian-Eulerian model. This modeling is based on ensemble-averaged mass and momentum equations for each phase (Ishi, 1975; Lahey and Drew, 2001). The momentum and continuity equations are solved for both phases that share the same pressure field. In order to couple two phases appropriate closure laws corresponding for interfacial forces should be provided.

For an incompressible flow without mass transfer between phases, the continuity and momentum equations are written as follows:

$$
\begin{gathered}
\nabla \cdot\left(\rho_{k} \alpha_{k} \vec{v}_{k}\right)=0 \\
\nabla \cdot\left(\rho_{k} \alpha_{k} \vec{v}_{k} \vec{v}_{k}\right)=-\alpha_{k} \nabla P+\alpha_{k} \rho_{k} \vec{g}+\nabla\left[\alpha_{k} \mu_{k}\left(\nabla v_{k}+\left(\nabla \vec{v}_{k}\right)^{T}\right)\right]+\vec{F}_{k}
\end{gathered}
$$

where $\rho, \alpha$ and $\mu_{k}$ are density, volume fraction and effective viscosity. The first term at the right hand side of momentum equation shows the pressure gradient and the second and third terms show the stress and gravity. The last term stands for the interfacial forces applied on phase k. Same equations are solved for the secondary phase p.

\subsection{Interfacial Forces}


In the present study three different interfacial forces namely, the drag, lift and turbulent dispersion forces were considered. Hence, the last term can be written as follows:

$$
\vec{F}_{k}=\vec{F}_{d, k}+\vec{F}_{\text {lift }, k}+\vec{F}_{t d, k}+\vec{F}_{s, k}
$$

where $\vec{F}_{d, k}, \vec{F}_{l i f t, k}, \vec{F}_{t d, k}$ and $\vec{F}_{s, k}$ denote the drag, lift, turbulent dispersion and interfacial tension forces, respectively.

\subsubsection{Drag Force}

The drag force is in the direction of the motion of dispersed phase which is quantified as follows.

$$
\vec{F}_{d, k}=\frac{3}{4 d_{p}} C_{d} \rho_{k} \alpha_{p}\left|\vec{v}_{p}-\vec{v}_{k}\right|\left(\vec{v}_{p}-\vec{v}_{k}\right)
$$

where, $\mathrm{Cd}$ and dp stand for the drag coefficient and the diameter of the dispersed droplets. The drag coefficient, $C_{d}$, is quantified using Schiller-Naumann model as follows:

$$
C_{d}=\left\{\begin{array}{cc}
\frac{24\left(1+0.15 R e^{0.687}\right)}{R e} & R e \leq 1000 \\
0.44 & R e>1000
\end{array}\right.
$$

where the relative Reynolds number, $R e$, is as follows:

$$
\operatorname{Re}=\frac{\rho_{k}\left|\vec{v}_{p}-\vec{v}_{k}\right| d_{p}}{\mu_{k}}
$$

\subsubsection{Lift Force}

The droplets moving in a shear flow are subjected to a lateral lift force. The arising lift force is perpendicular to the direction of the droplet's motion. The lift force is quantified as follows:

$$
\vec{F}_{\text {lift }, k}=-C_{L} \rho_{k} \alpha_{p}\left(\vec{v}_{k}-\vec{v}_{p}\right) \times\left(\nabla \times \vec{v}_{k}\right)
$$

For small bubbles and droplets, this force acts towards the pipe wall. However, large bubbles or droplets move toward the center of the pipe due to the substantial deformation. Tomiyama et al. (2002) developed an Eotvos dependent lift law that is capable of predicting the direction of the lift force. The modified version of tomiyama lift, proposed by Frank et al. (2004) is as follows:

where

$$
C_{L}=\left\{\begin{array}{cc}
\min \left[0.288 \tanh \left(0.121 R e_{p}\right), f\left(E O^{\prime}\right)\right] E O^{\prime}<4 \\
f\left(E O^{\prime}\right) & 4<E O^{\prime}<10 \\
-0.27 & 10<E O^{\prime}
\end{array}\right.
$$

$$
f\left(E O^{\prime}\right)=0.00105 E O^{\prime 3}-0.0159 E O^{\prime 2}-0.0204 E O^{\prime 3}+0.474
$$

where EO' is modified Eotvos number based on the deformable bubble or droplet $d_{h}$

$$
E O^{\prime}=\frac{g\left(\rho_{q-} \rho_{p}\right) d_{h}^{2}}{\sigma}
$$

The maximum horizontal dimension of a deformed droplet, $d_{h}$, can be evaluated by using the empirical correlation of Wellek et al. (1966)

$$
\begin{gathered}
d_{h}^{2}=d_{p}\left(1+0.163 E o^{0.757}\right)^{\frac{1}{3}} \\
E O=\frac{g\left(\rho_{q}-\rho_{p}\right) d_{p}^{2}}{\sigma}
\end{gathered}
$$


where $\sigma$ is surface tension, $\mathrm{g}$ is gravity and $d_{p}$ is droplet diameter.

\subsubsection{Turbulent dispersion force}

The turbulent dispersion force is computed by using Burns et al. (2004) model as follows:

$$
\overrightarrow{\mathrm{F}}_{\mathrm{td}, \mathrm{k}}=-\overrightarrow{\mathrm{F}}_{\mathrm{td}, \mathrm{p}}=\mathrm{C}_{\mathrm{TD}} \mathrm{K}_{\mathrm{pk}} \frac{\mathrm{D}_{\mathrm{k}}}{\sigma_{\mathrm{pk}}}\left(\frac{\nabla \alpha_{\mathrm{p}}}{\alpha_{\mathrm{p}}}-\frac{\nabla \alpha_{\mathrm{k}}}{\alpha_{\mathrm{k}}}\right)
$$

where $\mathrm{K}_{\mathrm{pk}}$ denotes the interface momentum exchange coefficient which is given by

$$
\mathrm{K}_{\mathrm{pk}}=\frac{\alpha_{\mathrm{k}} \alpha_{\mathrm{p}} \rho_{\mathrm{p}} \mathrm{f}}{\tau_{\mathrm{p}}}
$$

$\tau_{\mathrm{p}}$ denotes the particulate relaxation time which is calculated as follows.

$$
\tau_{\mathrm{p}}=\frac{\rho_{\mathrm{p}} \mathrm{d}_{\mathrm{p}}^{2}}{18 \mu_{\mathrm{k}}}
$$

The drag function, $\mathrm{f}$, was quantified using the Schiller-Naumann model mentioned in 2.2.1.

$$
\mathrm{f}=\frac{C_{d} R e}{24}
$$

The dispersion scalar is estimated by the turbulent viscosity of the continuous phase as follows:

$$
\mathrm{D}_{\mathrm{k}}=\mathrm{D}_{\mathrm{p}}=\mathrm{D}_{\mathrm{tk}}=\frac{\mu_{\mathrm{tk}}}{\rho_{\mathrm{k}}}
$$

A dispersion Prandtl number, $\sigma_{\mathrm{pq}}$, equal to 0.75 was used in this model. Moreover, $\rho_{q}$ is the density of the continuous phase and $\nabla \alpha_{\mathrm{p}}$ is the gradient of dispersed phase volume fraction. A turbulent dispersion coefficient equal to 1.5 was adopted in the present study.

\subsubsection{Interfacial Tension force}

The Continuum Surface Force (CSF) method, proposed by Brackbill et al. 1992 was used to model the interfacial tension force. Using this model results in a better prediction of the shape of interface for stratified flow. For a twophase flow this force is calculated as follows:

$$
F_{s, q}=\sigma k n \frac{\rho}{\frac{1}{2}\left(\rho_{p}+\rho_{q}\right)}
$$

Where, the surface normal, $\mathrm{n}$, and the curvature, $\mathrm{k}$, are defined as follows:

$$
\begin{gathered}
n=\nabla \alpha_{q} \\
k=\nabla \cdot \hat{n}, \hat{n}=\frac{n}{|n|}
\end{gathered}
$$

In order to consider the wall adhesion effect the contact angle of fluid with the wall is used to adjust the surface normal in the cells next to the wall. For a known contact angle of $\theta_{w}$, the surface normal in the cell next to the wall is determined as follows:

$$
\hat{n}=\hat{n}_{w} \cos \theta_{w}+\hat{t}_{w} \sin \theta_{w}
$$

where, $\hat{n}_{w}$ and $\hat{t}_{w}$ are the unit vectors normal and tangential to the wall, respectively.

\subsection{Droplet size}

Determination of the drop size of the secondary phase is essential prior to proceed the numerical solution of the two-fluid model described above. The drop size is one of the critical parameters affecting the CFD solution. The maximum diameter of the droplet is determined from the balance of turbulent stresses tending to break a drop and the cohesive interfacial force that try to restore the original shape (Cai et al., 2012; Pacek et al., 1998; Sathe et al., 2010). In this study, the equation proposed by Brauner (2001) was used to estimate the maximum diameter of the secondary phase. 


$$
\mathrm{d}_{\max }=2.22 \mathrm{D}\left(\frac{\rho_{\mathrm{k}} \mathrm{U}_{\mathrm{k}}^{2} \mathrm{D}}{\sigma}\right)^{-0.6}\left(\frac{\rho_{\mathrm{m}}}{\rho_{\mathrm{k}}\left(1-\varepsilon_{\mathrm{p}}\right)} \mathrm{f}\right)^{-04}\left(\frac{\varepsilon_{\mathrm{p}}}{1-\varepsilon_{\mathrm{p}}}\right)^{0.6}
$$

where $\mathrm{D}$ is the internal diameter of the pipe and $\varepsilon_{\mathrm{p}}$ denotes the volume fraction of the dispersed phase at the inlet. Furthermore, $\mathrm{k}, \mathrm{p}$ and $\mathrm{m}$ indicate the continuous phase, the dispersed phase and the mixture, respectively. According to the correlation proposed by Angeli and Hewitt (2000b), the Sauter mean diameter is 0.48 of the maximum diameter. In this study, a uniform droplet size equal to the Sauter mean diameter was assumed throughout the computational domain. As mentioned, for all the simulations performed in this study, the water cut was below phase inversion point. Hence, the oil was considered as the primary phase and the water was considered as the secondary phase.

\subsection{Turbulence Model}

Turbulence modeling is required to determine the effective viscosity in the Navier-Stokes equations. Turbulence has a significant effect on the radial profile of the velocity of both phases and interfacial forces experienced by the secondary phase. Previous studies revealed that the droplets may have a significant interaction with the turbulent eddies of the continuous phase, according to the sizes of the eddies and the droplets (Angeli and Hewitt, 2000b; Elgolbashi, 1991). However, there is no standard turbulence model tailored for two phase flows. Traditionally, twoequation turbulence models are used to investigated the flow field in such multiphase flows. The k- $\varepsilon$ model is robust and has been used and validated extensively in industrial internal flow applications (Roudsari et al., 2012). In the present study the standard k- $\varepsilon$ model was used to model turbulent flow in two-phase oil-water flow. A per-phase approach was used in which a set of $\mathrm{k}$ and $\varepsilon$ transport equations are solved for each phase. The per-phase standard $\mathrm{k}-\varepsilon$ model equations used in this study are the standard form mentioned in Fluent's theory guide (2011). The turbulent viscosity is calculated as follows:

$$
\mu_{t, k}=\rho_{k} C_{\mu} \frac{k_{k}^{2}}{\varepsilon_{k}}
$$

where $C_{\mu}$ is 0.09 . The effect of dispersed phase on the turbulence of the primary phase, $\mu_{t, k, i}$, was modeled using the model proposed by Sato et al. (1981). According to this model the induced turbulence by the dispersed phase is calculated as follows:

$$
\mu_{t, k, i}=\rho_{k} C_{\mu, p} \alpha_{p} d_{p}\left|\vec{v}_{p}-\vec{v}_{k}\right|
$$

The constant was set to $C_{\mu, p}=0.6$. The effective viscosity of the continuous phase determined as being composed of the molecular viscosity, turbulent viscosity and the induced viscosity by the dispersed phase.

The pressure-velocity coupling was achieved via Phase Coupled SIMPLE (PC-SIMPLE) method which is the extension of Semi-Implicit Method for Pressure-Linked Equations (SIMPLE) proposed by Patankar (1980) for multiphase flows.

A first-order upwind scheme was used to determine the face fluxes in the momentum and phase transport equations. The resulting algebraic linear system, from integrating the governing transport equations over control volumes, was solved using the Gauss-Seidel iterative method and the Algebraic Multi-Grid (AMG) method. To ensure the stability and convergence of the iterative calculation, lower under-relaxation factors were chosen. The ANSYS FLUENT 15.0 package was used to solve all transport equations.

\section{Geometry and Boundary Conditions}

In order to verify the accuracy of the CFD model a comprehensive comparison with experimental data is essential. Hence, numerical simulations were first carried out for flow conditions and geometry configurations with available experimental data. Table. 1 shows a brief description of the geometry of pipe and fluid properties that were used in the experiment (Elseth, 2001). Numerical simulations were performed for a horizontal pipe with internal diameter and lengths of $0.056 \mathrm{~m}$ and $15 \mathrm{~m}$, respectively.

In the experiment, oil and water were introduced into the pipe without any premixing (Elseth, 2001). In order to satisfy the experimental condition, two velocity-inlet boundary conditions were applied at the inlet through which oil and water were introduced separately. The oil and water entered the pipe from top and bottom, respectively. By varying the inlet velocity of oil and water different mixture velocities and water cuts were imposed at the inlet to satisfy the operating conditions of the experiment. The turbulent intensity and hydraulic diameter were specified at the velocity inlets. All the simulation in this study were conducted for water cuts below the phase inversion point. Hence, the oil was considered as a primary phase.

Pressure outlet boundary condition with the gage pressure of zero was specified at the outlet which is compatible with the experiment (Elseth, 2001). A no-slip boundary condition was imposed at the wall of the pipe. The effect of surface wettability was imposed by adjusting the contact angle at the wall. The steel pipe was considered as a 
hydrophilic surface. Due to the symmetric behavior of oil-water flows, a symmetric boundary condition was adopted which, in turn, reduced the computational time. A grid sensitivity analysis was performed through which a grid consist of 304,000 hexahedral cells with refinement near the wall was found to be appropriate for modeling the experiments conducted by (Elseth, 2001). Fig. 1 shows the grid and boundary conditions. The numerical and experimental results were obtained at the pipe cross section located $11.3 \mathrm{~m}$ downstream the inlet.

The same boundary conditions and grid size were applied for two other pipes with the internal diameter of $0.025 \mathrm{~m}$ and $0.1 \mathrm{~m}$. For the larger pipe, with internal diameter of $0.1 \mathrm{~m}$, a longer length equal to $20 \mathrm{~m}$ was modeled to insure the establishment of fully developed flow condition. All the grids were generated using GAMBIT 2.3.16 (GAMBIT, 2006).

\section{Results and Discussions}

Numerical simulations were first performed for oil-water flows in a horizontal pipe with the internal diameter of $0.056 \mathrm{~cm}$. Fig 2-7 show the distributions of water volume fraction across the pipe cross section as obtained by the CFD model and the experimental data reported by (Elseth, 2001). Fig. 2-4 show the water distribution for input water cut of 0.1 and for three different velocities. As seen in Fig. 2(a), at low velocity of $1 \mathrm{~m} / \mathrm{s}$ a free layer of oil is flowing at the top of the pipe, while a dispersion of water in oil is observed at the bottom. According to this figure the water volume fraction at the bottom of pipe is the highest. Fig. 2(b) shows the contours of water fraction at the pipe cross section as obtained by the CFD model. Fig. 3 and Fig. 4 show the water distribution for higher velocities of $1.5 \mathrm{~m} / \mathrm{s}$ and $2 \mathrm{~m} / \mathrm{s}$, respectively. As seen in these figures, for a constant input water cut, as the flow velocity increases the water volume fraction at the bottom of pipe decreases. From these figures, it is obvious that there is no continuous layer of water at the bottom of pipe. A comparison among the obtained CFD results and the experimental data indicate that the model can predict the water distributions with reasonable accuracy(see Fig 2(a),3(a) and 4(a)).

Fig. 5-7 display the distribution of water for a higher input water cut of 0.2 at three different velocities. Fig. 5 shows the distribution of water at low velocity of $1 \mathrm{~m} / \mathrm{s}$. According to Fig. 5(a) both the experimental and numerical results revealed the formation of a free water layer at the bottom of pipe. This figure shows a reasonable agreement between the numerical results and corresponding experimental data. Fig. 5(b) shows the contours of water fraction across the pipe cross section. As seen in this figure a free layer of water is flowing at the bottom. This figure also shows the capability of CFD model in predicting the hydrophilic property of steel pipe. As seen in this figure, a concave interface was predicted by CFD model which is consistent with the experimental data. The surface wettability of pipe is measured as an oil-water contact angle. The hydrophilic property of steel pipe was taken into account by considering an oil-water contact angle equal to $30^{\circ}$ which is compatible with experiments. Fig. 6 shows the water distribution for higher flow velocity equal to $1.5 \mathrm{~m} / \mathrm{s}$ while the input water cut was kept constant. As seen in this figure, by increasing the flow velocity, water entrainment increases and a free water layer cannot be sustained. Comparison of Fig 5(b) and Fig. 6(b) shows this fact with more clarity. Fig. 7 depicts the water distribution for a higher velocity of $2 \mathrm{~m} / \mathrm{s}$ and an input water cut equal to 0.2. As seen in Fig. 7(a) both the experimental data and the CFD results show a dens dispersion of water in oil at the bottom of pipe. Fig. 7(b) shows the distribution of water at pipe cross section with more clarity.

These figures clearly indicate that the input water-cut and flow velocity are two critical parameters that influence the water distribution and the type of wetting. The present results reveal the capability of CFD model in predicting the water distribution and the type of wetting. Except for Fig. 5, in which a continuous layer of water (water wetting) is observed at the bottom of pipe, for the other cases a dispersion of water in oil is observed. Previous studies indicate that a dense dispersion of water in oil should be considered as an intermittent wetting were the water and oil may alternatively wet the wall. Although, the corrosion rate for intermittent wetting is significantly lower than that in water wetting regime, the corrosion risk cannot be neglected (Cai et al., 2012).

A proper design considering the critical velocity for transition to oil wetting can be a major step toward mitigating the corrosion risk. However, the effect of flow velocity on sand particle deposition should be also taken into account. The solid particles tend to be encapsulated by water. Deposition of wet sand particles in pipelines can result in an under deposit corrosion that often manifest as localized pitting (Larsen, 2013).

It is worth mentioning that although increasing the flow velocity increases the probability of oil wetting an insufficient increase of velocity with incomplete water entrainment may result in higher corrosion rate (Wang and Zhang; 2015). Hence, it is crucial to predict the minimum velocity, required for oil wetting, with reasonable accuracy.

In order to increase the confidence regarding the accuracy of the present CFD approach in predicting the phase distributions under different working conditions numerical simulations were performed for oil-water flows in a larger pipe with the internal diameter of $0.1 \mathrm{~m}$. The oil viscosity and density were $4.7 \mathrm{cp}$ and $830 \mathrm{~kg} / \mathrm{m}^{3}$, respectively. Furthermore, the interfacial tension of oil and water was $0.0262 \mathrm{~N} / \mathrm{m} \mathrm{(Li,} 2009$ and Tang et al., 2007). Numerical simulations were performed for a mixture velocity of $0.9 \mathrm{~m} / \mathrm{s}$. The effect of input water cut on the type of wetting 
was studied by considering three different water cuts. The numerical results regarding the vertical distribution of water volume fraction across the pipe cross section is shown in Fig. 8. As seen in this figure, for water cut equal to 0.12 , a thin free water layer is formed at the bottom of pipe which is considered as a fully water wetting condition. However, for a low water cut of 0.04 , the water volume fraction at the bottom of pipe is less than $40 \%$, which in turn, introduces a fully oil wetting condition. The numerical results for water cut equal to 0.08 shows a dense dispersion of water in oil at the bottom of pipe which is considered as an intermittent wetting. Fig. 9 shows the contours of water volume fraction for different input water cuts as obtained by the CFD model. The predicted types of wetting by the CFD model agree well with the experimental observation (Li, 2009 and Tang et al., 2007). Furthermore, Table. 2 shows the measured corrosion rates for these water cuts (Li, 2009 and Tang et al., 2007). The table clearly shows that for the lowest water cut of 0.04 , the corrosion rate is zero which is due to the occurrence of fully oil wetting. While, for the highest water cut of 0.12 , a high corrosion rate is observed as a result of fully water wetting. Moreover, for water cut equal to 0.08 , a lower corrosion rate is observed due to the occurrence of an intermittent wetting.

As mentioned before, the internal diameter of pipeline may affect the flow pattern and the type of wetting. In order to investigate the influence of pipe diameter on the water distribution and type of wetting, numerical simulations were carried out for three different pipes with the internal diameter of $0.025,0.056$ and $0.1 \mathrm{~m}$, respectively. The density and viscosity of oil were $790 \mathrm{~kg} / \mathrm{m} 3$ and $1.64 \mathrm{cP}$, respectively. Whereas, the interfacial tension of oil-water was $0.043 \mathrm{~N} / \mathrm{m}$. Fig. 10(a-f) illustrate the effect of pipe diameter on the water distribution and type of wetting. Numerical results of the distribution of water for different velocities and water-cuts clearly indicate that an increase in pipe diameter results in an increase in the water volume fraction at the bottom of pipe. Hence, it can be concluded that as we increase the diameter of pipe the probability of water wetting increases, which in turn, introduces a potential of corrosion attack. As seen in these figures, for a small diameter pipe a water wetting is not observed even at the lowest velocity and the highest water-cut (see Fig. 10(d)). However, for a large diameter pipe water wetting is observed even at the highest velocity of $2 \mathrm{~m} / \mathrm{s}$ (see Fig. 10(f)). Although a small diameter pipeline increases the probability of oil wetting, it would induce a higher pressure drop and more energy consumption. Hence, an optimized pipe size considering different undesirable aspects should be selected (Wang and Zhang; 2015).

In order to study the effect of oil viscosity on the type of wetting, numerical modeling was performed for three different viscosities, while the other parameters were kept constant. The mixture velocity, pipe diameter and input water cut were $1.3 \mathrm{~m} / \mathrm{s}, 0.1 \mathrm{~m}$ and 0.1 , respectively. The oil density and interfacial tension were $823 \mathrm{Kg} / \mathrm{m} 3$ and $0.0405 \mathrm{~N} / \mathrm{m}$, respectively. Furthermore, the steel surface was hydrophilic with a contact angle of $73^{\circ}$. The influence of oil viscosity on water distribution is illustrated in Fig. 11. According to the present numerical results using the lightest oil with viscosity of $2.7 \mathrm{cP}$ results in a water wetting condition at the bottom of pipe. This finding agrees well with the published experimental data by (Kee et al., 2016). By increasing the oil viscosity to $7 \mathrm{cP}$, while other parameters are kept constant, a higher degree of dispersion occurs inside the pipe. As a result, the volume fraction of water at the bottom of pipe decreases. As seen in this figure, for higher viscosity of $7 \mathrm{cP}$ an intermittent wetting is observed at the bottom of pipe, which in turn, reduces the corrosion rate. Furthermore, this figure shows that by further increase of oil viscosity to $15 \mathrm{cP}$, the water fraction at the bottom of pipe further decreases and becomes less than 0.4. Such condition can be considered as an oil wetting condition where the corrosion rate is negligible. The present CFD results suggest that an increase in the viscosity of oil results in a higher level of dispersion. In the other world, it can be said that high viscous oil is capable of sweeping more water from the bottom of a pipe, thereby reducing the corrosion risk.

Fig. 12 shows the influence of oil density on the flow pattern and the type of wetting. According to the present numerical results as we decrease the density of oil the tendency of system for stratification increases. Whereas, an increase in the density of oil results in a higher level of mixing between two phases. From this figure, it can be concluded that for low density oils the probability of water wetting and corrosion risk is higher than that of high density oils provided the other properties such as viscosity of oil remain constant. It is worth mentioning that there is a correlation between the density and viscosity of oils. At a certain temperature, heaver oils are more viscous. (Sanchez-Minero et al., 2014). Hence, they are capable of sweeping more water from the bottom of pipe.

Fig. 13 illustrates the effect of interfacial tension of oil and water on the flow pattern and the type of wetting. Numerical simulations were carried out for four different interfacial tensions ranging from $0.005 \mathrm{~N} / \mathrm{m}$ to $0.06 \mathrm{~N} / \mathrm{m}$, while other properties were kept constant. From this figure it is obvious that a decrease in interfacial tension significantly promotes the water entrainments. Whereas, as a results of an increase in interfacial tension the water phase tends to break out and retain its continuity.

It is well known that using inhibitors is an effective way to reduce the interfacial tension and mitigate the corrosion risk ( $\mathrm{Li}$ et al., 2014). The obtained results of the present study clearly show the effectiveness of reducing the interfacial tension by using inhibitors. The capability of CFD model in predicting the water distribution across a pipe cross section can be a great help for using the inhibitors in a more effective way. It should be mentioned that using inhibitors may also alter the flow pattern by changing the surface wettability which is measured as an oil- 
water contact angle ( $\mathrm{Li}$ et al., 2014). However, the present study only focuses on the effect of interfacial tension. Hence, in all of the simulations the same contact angle was considered. For the present oil-water flow in a steel pipe the interior surface of pipe was considered as a hydrophilic surface with a contact angle of $30^{\circ}$ which is compatible with experiments. Furthermore, keeping the contact angle as a constant value allows us to draw a better comparison of the effect of different surface tensions.

Fig. 14 shows the contours of water fraction at the same pipe cross section for two different interfacial tensions. As seen in Fig. 14(a), for a system with low interfacial tension a high level of dispersion is observed and a continuous layer of water cannot be formed at the bottom of pipe, thereby mitigating the corrosion risk. However, for the same system with higher interfacial tension a stratified flow pattern is formed in the pipe where a thick free water layer is flowing at the bottom of pipe, which in turn, introduces a serious menace of corrosion attack (see Fig. 14(b)).

\section{Conclusions:}

Numerical simulation of two-phase oil-water flow was carried out by taking advantage of the Eulerian-Eulerian approach. The standard k- $\varepsilon$ model was adopted to account for the turbulence effects. The accuracy of the results was examined by making a comparison with available experimental data.

According to the present numerical results the multi-phase CFD model could predict the characteristics of oil-water flow and the types of wetting with reasonable accuracy. The numerical model was used to investigate the effect of different parameters on the type of wetting in a two-phase oil-water flow.

The obtained numerical results of this study, for water cuts below phase inversion point, suggest the following conclusions.

1. For a constant water cut, fluid properties and geometry, an increase in flow rate results in a higher level of dispersion and there exist a critical velocity beyond which there will be no water wetting.

2. For a constant flow rate and water cut as the diameter of pipe increases the probability of water wetting and corrosion risk increases.

3. For a constant flow rate and water cut as the viscosity of oil increases the likelihood of water wetting and corrosion risk decreases.

4. A decrease in interfacial tension of oil and water results in a higher water entrainment and a decrease in corrosion risk.

5. The higher the density of the oil the less the likelihood of water wetting and corrosion provided the other properties are kept constant.

\section{Acknowledgments}

This research was undertaken at the Lloyd's Register Foundation Research Centre of Excellence at Pusan National University. Lloyd's Register Foundation (LRF), a UK registered charity and sole shareholder of Lloyd's Register Group Ltd, invests in science, engineering and technology for public benefit, worldwide.

\section{References}

Al-Yaari, M.A., Abu-Sharkh, B.F., 2011, CFD prediction of stratified oil-water flow in a horizontal pipe. Asian Trans. Eng, 1(5), 6875.

Adams, C.D., Garber, J.D., Walters, F.H., Singh, C., 1993. Verification of computer modeled tubing life predictions by field data, NACE Corrosion/93, Paper No. 93082.

Angeli, P., Hewitt, G.F., 2000a. Flow structure in horizontal oil-water flow. Int. J. Multiphase Flow. 26, 1117-1140.

Angeli, P., Hewitt, G.F., 2000b. Drop size distributions in horizontal oil-water dispersed flows. Chem. Eng. Sci. 55, $3133-3143$.

Bestion, D., 2014. The difficult challenge of a two-phase CFD modelling for all flow regimes, Nucl. Eng. Des. 279, 116-125.

Bockris, J.OM., Drazic, D., Despic, A.R., 1961. The electrode kinetics of the deposition and dissolution of iron, Electrochemica Acta, 4(2-4)pp.325-361. 
Brackbill, J.U., Kothe, D.B., Zemach, C., 1992. A Continuum Method for Modeling Surface Tension. J.Comput.Phys. 100.335-354.

Brauner, N., 2001. The prediction of dispersed flows boundaries in liquid-liquid and gas-liquid systems. Int. J. Multiphase Flow. 27, 885-910.

Burlutsky, E., Turangan, C.B., 2015. A computational fluid dynamics study on oil-in-water dispersion in vertical pipe flows. Chem. Eng. Res. Des. 93, 48-54.

Burns, A.D., Frank, T., Hamill, I., Shi, J.M., 2004. The Favre averaged drag model for turbulent dispersion in Eulerian multi-phase flows. In5th international conference on multiphase flow, ICMF(Vol. 4).

Cai, J., Nesic, S., De-Waard, C., 2004. Modeling of water wetting in oil-water pipe flow, CORROSION 2004, Paper No. 04663.

Cai, J., Li, C., Tang, Z., Ayello, F., Richter, S., Nesic, S., 2012. Experimental study of water wetting in oil-water two-phase flowhorizontal flow of model oil. Chem. Eng. Sci. 73, 334-344.

Craig, B.,1998. Predicting the conductivity of water-in-Oil solutions as a means to estimate corrosiveness, CORROSION, 54(8).PP.657662.

De Waard, C., Lotz, U., 1993, Prediction of CO2 corrosion of carbon steel, Corrosion/93, paper no. 69 (Houston, TX: NACE International).

De Waard, C., Lotz, U., Dugstad, A., 1995. Influence of liquid flow velocity on CO2 corrosion a semi-empirical model, Corrosion/95, paper no. 128 (Houston, TX: NACE International).

De Waard, C., Smith, L., Craig, B.D., 2001. The influence of crude oil on well tubing corrosion rates, CORROSION/2003, Paper 3629.

Elgolbashi, S., 1991. Particle-laden turbulent flow: direct simulation and closure models. Appl. Sci. Res. 48, $301-314$.

Elseth, G., 2001. An experimental study of oil/water flow in horizontal pipes. PhD Thesis, The Norwegian University of Science and Technology, Tronheim.

Fluent User's Guide, 2011. Release 14, Ansys Inc, USA.

Frank, T., Shi, J., Burns, A.D., 2004. Validation of Eulerian multiphase flow models for nuclear safety applications, $3^{\text {rd }}$ international symposium on two-phase flow modeling and experimentation, Pisa, Italy, 22-24, Sep. 2004.

Gambit Users's Guide., 2006. Release 2.3.16, ANSYS Inc, USA.

Gao, H., Gu, H.Y., Guo, L.J., 2003. Numerical study of stratified oil-water two-phase turbulent flow in a horizontal tube. Int. J. Heat Mass Transfer. 46, 749-754.

Gray, L.G.S., Anderson, B.G., Danysh, M.J., Tremaine, P.R., 1989a. Mechanism of carbon steel corrosion in brines containing dissolved carbon dioxide at $\mathrm{pH}=4$, Corrosion/89, Paper no. 464 (Houston, TX: NACE International).

Gray, L.G.S., Anderson, B.G., Danysh, M.J., Tremaine, P.R., 1989b, Effect of pH and temperature on the mechanism of carbon steel corrosion by aqueous carbon dioxide, Corrosion/90, Paper no. 40 (Houston, TX: NACE International).

Hamad, F.A., He, S., Khan, M.K., Bruun, H.H., 2013. Development of kerosene-water two-phase up-flow in a vertical pipe downstream of a $90^{\circ}$ bend. Can. J. Chem. Eng. 91, 354-367.

Hinz, J.O., 1955, Fundamentals of the hydrodynamic mechanism of splitting in dispersion process, AIChE Journal, 1(3), $289-295$.

IIman, M.N., Kusmono., 2014. Analysis of internal corrosion in subsea oil pipeline, Case Stud. Eng. Fail. Anal. 2(1). pp.1-8.

Ishi, M., 1975, Thermo-Fluid Dynamics Theory of Two Phase Flow, Eyrolles, Paris.

Kee, K.E., Richter, S., Babic, M., Nesic, S., 2014. Flow patterns and water wetting in oil-water two phase flow- A flow loop study, 
CORROSION-2014, Paper No. 4068.

Kee, K.E., Richter, S., Babic, M., Nesic, S., 2016. Experimental Study of Oil-Water Flow Patterns in a Large Diameter Flow LoopThe Effect on Water Wetting and Corrosion. CORROSION. 72(4), 569-582.

Kermani, M.B., Harrop, D., 1996. The impact of corrosion on oil and gas industry, SPE Production and Operations, 11, 3, (1996);pp. 186-190.

Kumara, W.A.S., Halvorsen, B.M., Melaaen, M.C., 2009. Pressure drop, flow pattern and local volume fraction measurement of oilwater flow in pipes. Meas. Sci. Technol. 20, 1-18.

Lahey, R.T., Drew, D.A., 2001. The analysis of two-phase flow and heat transfer using a multidimensional, four field, two-fluid model, Nucl. Eng. Des. 204(1), 29-44.

Larsen, K.R., 2013. Managing Corrosion of Pipelines that Transport Crude Oils, Materials Performance. 52(5), 28-35.

Li, C., Tang, X., Ayello, F., Cai, J., Nesic, S., 2006. Experimental study on water wetting and CO2 corrosion in oil-water two-phase flow, NACE Paper No. 06595, 2006.

Li, C., 2009, Effect of corrosion inhibitor on water wetting and carbon dioxide corrosion in oil-water two-phase flow, PhD Thesis, Ohio University

Li, C., Richter, S., Nešicl, S., 2014. How Do Inhibitors Mitigate Corrosion in Oil-Water Two-Phase Flow Beyond Lowering the Corrosion Rate?, Corrosion,70(9), pp.958-966.

Lovick, J., Angeli, P., 2004a. Experimental studies on the dual continuous flow pattern in oil-water flows. Int. J. Multiphase Flow. 30, $139-157$.

Mohd, M.H., Lee, B.J., Cui, Y., Paik, K.K., 2015. Residual strength of corroded subsea pipelines subject to combined internal pressure and bending moment, Ships and Offshore Structures, 10(5), pp.554-564.

Mohd, M.H., Paik, J.K., 2013. Investigation of the corrosion progress characteristics of offshore subsea oil well tubes, Corros. Sci. 64, pp.130-141.

Monzon, C.F.T., 2006. Theoretical modelling of oil-water flow in horizontal and near horizontal pipes. PhD Thesis, University of Tulsa.

Nesic, S., Postlethwaite, J., Olsen, S., 1995. An electrochemical model for prediction of CO2 Corrosion, Corrosion/ 95 , paper no. 131 (Houston, TX: NACE International, 1995).

Nesic, S., Nordsveen, M., Nyborg, R., Stangeland, A., 2003. A mechanistic model for CO2 corrosion of mild steel in the presence of protective iron carbonate scales- part $\Pi$ : A numerical experiment, Corrosion 59, 489.

Nesic, S., Cai, J., Lee, K.L.J., 2005. A multiphase flow and internal corrosion prediction model for mild steel pipelines, CORROSION 2005, Paper No. 05556.

Nesic, S., 2007. Key issues related to modelling of internal corrosion of oil and gas pipelines - a review. Corros. Sci. 49, $4308-4338$.

Nesic, S., 2012. Effects of Multiphase Flow on Internal CO2 Corrosion of Mild Steel Pipelines. Energy Fuels. 26, 4098-4111.

Nordsveen, M., Nesic, S., Nyborg, R., Stangeland, A., 2003. A mechanistic model for carbon dioxide corrosion of mild steel in the presence of protective iron carbonate scales- part 1:Theory and verification, Corrosion 59, 443.

Norsok, NORSOK Standard M-506., 2005, CO2 corrosion prediction model, Strandveien.

Nyborg, R., 2005. Controlling internal corrosion in oil and gas pipelines. Business Briefing: Exploration \& Production: The Oil \& Gas Review,2, 70-74. 
Nyborg, R., 2010. CO2 corrosion models for oil and gas production systems. CORROSION 2010. NACE International.

Pacek, A.W., Man, C.C.,. Nienow, A.W., 1998. On the Sauter mean diameter and size distributions in turbulent liquid-liquid dispersions in a stirred vessel, Chem. Eng. Sci. 53(11), 2005-2011.

Papavinasam, S., Doiron, A., Revie, R.W., 2010. Model to predict internal pitting corrosion of oil and gas pipelines, Corrosion, 66(3), 035006-035006.

Parvini, M., Dabir, B., Mohtashami, S, S.A., 2010. Numerical simulation of oil dispersions in vertical pipe flow. J. Jpn. Pet. Inst. 53, $42-54$.

Patankar, S., 1980.Numerical heat transfer and fluid flow. CRC Press.

Pouraria, H., Paik, J.K., Seo, J.K., 2013, Modeling of oil-water flow in horizontal pipeline using CFD technique, ASME 2013, 32nd International Conference on Ocean, Offshore and Arctic Engineering. American Society of Mechanical Engineers.

Pouraria, H., Seo, J.K., Paik, J.K., 2016. Numerical modelling of two-phase oil-water flow patterns in a subsea pipeline. Ocean Engineering. 115, 135-148.

Prosperetti, A., Tryggvason, G., 2007. Computational methods for multiphase flows, Cambridge University Press, Cambridge/Sao Paulo.

Roudsari, S.F., Turcotte, G., Dhib, R., Mozaffari, F.E., 2012. CFD modelling of the mixing of water in oil emulsion. Comput. Chem. Eng. 45, 124-136.

Sanchez-Minero, F., Sanchez-Reyna, G., Ancheyta, J., Marroquin, G., 2014. Comparison of correlations based on API gravity for predicting viscosity of crude oils. Fuel. 138, 193-199.

Sathe, M.J., Deshmukh, S.S., Joshi, J.B., Koganti, S.B., 2010. Computational fluid dynamics simulation and experimental investigation: study of two-phase liquid-liquid flow in a vertical Taylor-Couette contactor. Ind. Eng. Chem. Res. 49, 14-28.

Sato, Y., Sekoguchi, K., 1975. Liquid velocity distribution in two-phase bubbly flow. Int. J. Multiphase Flow. 2, 79-95..

Smith, L.M., 1987. Controlling factors in the rate of CO2 corrosion, UK Corrosion 87 Brighton.

SP0208, N.A.C.E. (2008). Internal corrosion direct assessment methodology for liquid petroleum pipelines. Houston, TX:NACE International.

Tang, X., Li, C., Ayello, F., Cai, J., Nesic, S., Cruz, C.I.T., AL-Khamis, J.N., 2007. Effects of oil type on phase wetting transition and corrosion in oil-water flow, NACE Paper No. 07170

Tomiyama, A., Tamai, H., Zun, I., Hosokawa, S., 2002. Transverse migration of single bubbles in simple shear flows. Chem. Eng. Sci. $57,1849-1858$.

Torres, C.F., Mohan, R.S., Gomez, L.E., Shoham, O., 2016. Oil-Water Flow Transition Prediction in Horizontal Pipes. Trans. ASME: J. Energy Resour. Technol. 138(2), 022904.

Walvekar, R.G., Choong, T.S.Y., Khalid, H.M., Chuah, T.G., 2009. Numerical study of dispersed oil-water turbulent flow in horizontal tube. J. Petrol. Sci. Eng. 65, 123-128.

Wang, S. ., George, K., Nesic, S., 2004. High pressure CO2 corrosion electrochemistry and the effect of acetic acid, CORROSION/2004, paper no. 375 (Houston, TX: NACE International, 2004).

Wang, Z.L., Zhang, J., Wang, Z.M., Zhou, L., Han, X., Li, Q.F., Gao, S., 2014. Emulsification reducing the corrosion risk of mild steel in oil-brine mixtures, Corros. Sci. 86, pp.310-317.

Wang, Z.M., Zhang, J., 2015. Corrosion of multiphase flow pipelines: the impact of crude oil, Corros Rev. 1-24.

Wellek, R.M., Agrawal, A.K., Skelland, A.H.P., 1966. Shape of liquid drops moving in liquid media. AIChE Journal,12(5), pp.854-862. 
Wicks, M., Fraser, J.P., 1975. Entrainment of water by flowing oil, Materials Performance, 14(5), 9-12.

Xu, X.X., 2007. Study on oil-water two-phase flow in pipelines, J. Petrol. Sci. Eng. 59, 43-58.

Yamoah, S., Martínez-Cuenca, R., Monrós, G., Chiva, S., Macián-Juan, R, 2015, Numerical investigation of models for drag, lift, wall lubrication and turbulent dispersion forces for the simulation of gas-liquid two-phase flow, Chem. Eng. Res. Des. 98, 17-35.

Yao, W., Bestion, D., Coste, P., 2004. A three dimensional two-fluid modelling of stratified flow with condensation for pressurized thermal shock investigations. Nucl. Technol. 152, 129-142.

Yusuf, N., Al-Wahaibi, Y., Al-Wahaibi, T., Al-Ajmi, A., Olawale, A.S., Mohammed, I.A., 2012. Effect of oil viscosity on the flow structure and pressure gradient in horizontal oil-water flow. Chem. Eng. Res. Des. 90, 1019-1030.

Table 1. Description of the properties of the fluids and the geometry used in the experiment (Elseth, 2001). 
Experimental condition

\begin{tabular}{cc}
\hline Pipe diameter & $0.0563 \mathrm{~m}$ \\
Pipe roughness & $0.00001 \mathrm{~m}$ \\
Pipe length & $15 \mathrm{~m}$ \\
Oil density & $790 \mathrm{~kg} / \mathrm{m} 3$ \\
Oil viscosity & $0.00164 \mathrm{~Pa} . \mathrm{s}$ \\
Water density & $1000 \mathrm{~kg} / \mathrm{m} 3$ \\
Water viscosity & $0.00102 \mathrm{~Pa} . \mathrm{s}$ \\
Interfacial tension & $0.043 \mathrm{~N} / \mathrm{m}$ \\
\hline
\end{tabular}



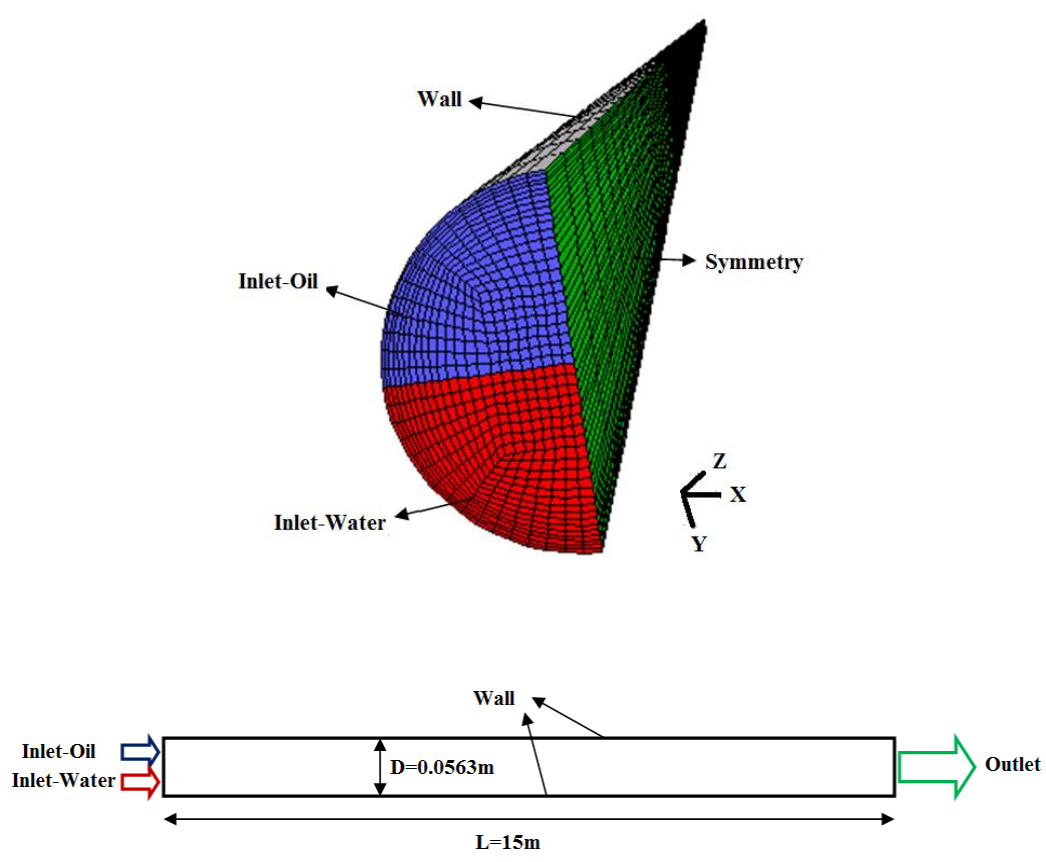

Fig. 1. The used grid and boundary condition. 


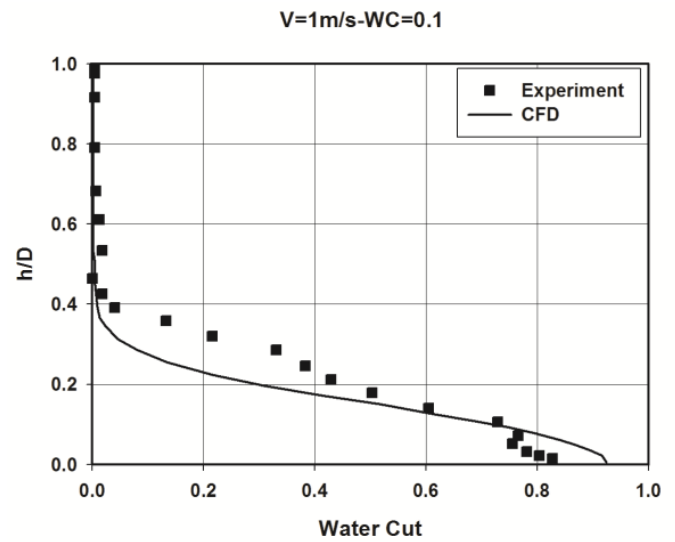

(a)
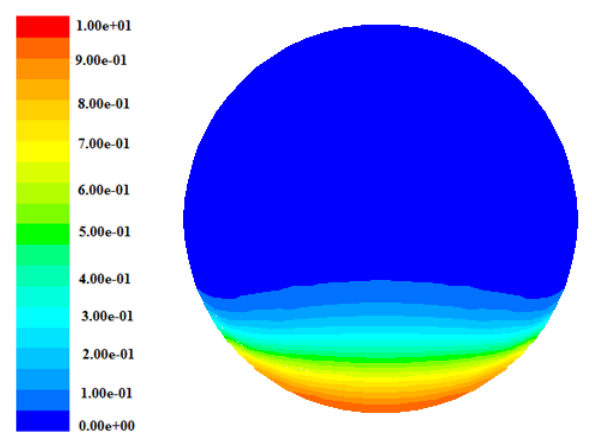

(b)

Fig. 2. Distribution of the water volume fraction across the pipe for an input water cut of $10 \%$ at a mixture velocity of $1 \mathrm{~m} / \mathrm{s}$. (a) Vertical distribution of the water fraction as predicted by the CFD model and obtained by measurement, (b) contours of the water volume fraction.

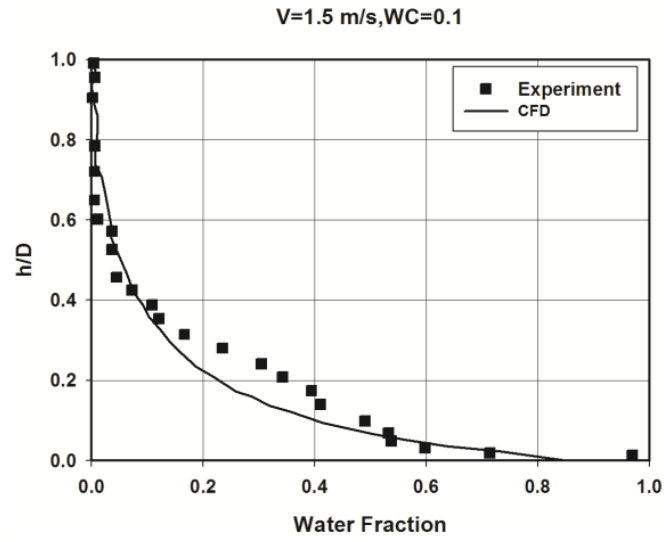


(a)

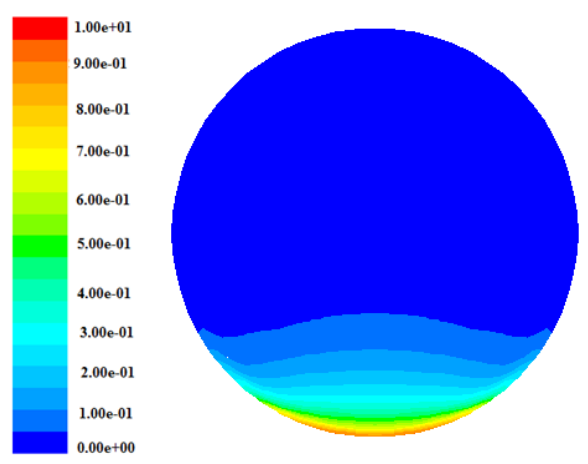

(b)

Fig. 3. Distribution of the water volume fraction across the pipe for an input water cut of $10 \%$ at a mixture velocity of $1.5 \mathrm{~m} / \mathrm{s}$. (a) Vertical distribution of the water fraction as predicted by the CFD model and obtained by measurement, (b) contours of the water volume fraction. 


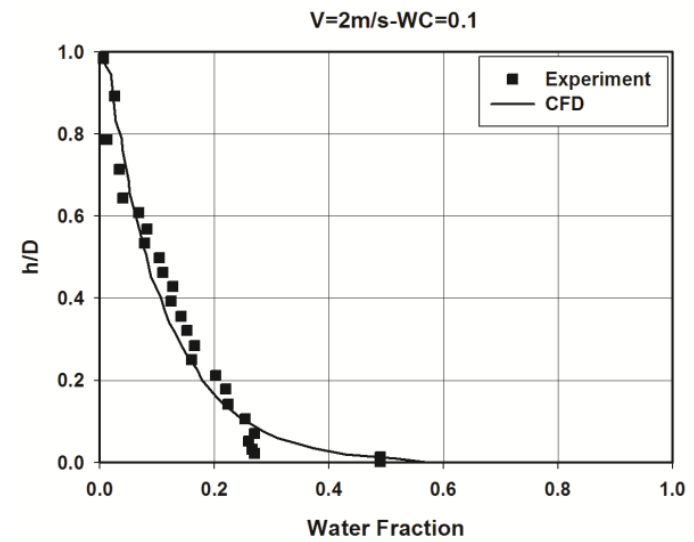

(a)
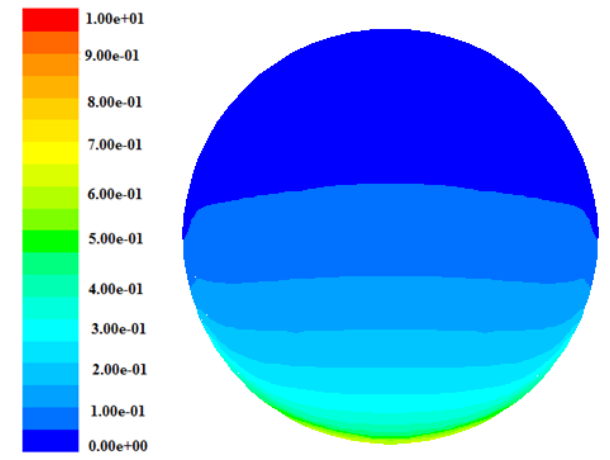

(b)

Fig. 4. Distribution of the water volume fraction across the pipe for an input water cut of $10 \%$ at a mixture velocity of $2 \mathrm{~m} / \mathrm{s}$. (a) Vertical distribution of the water fraction as predicted by the CFD model and obtained by measurement, (b) contours of the water volume fraction. 


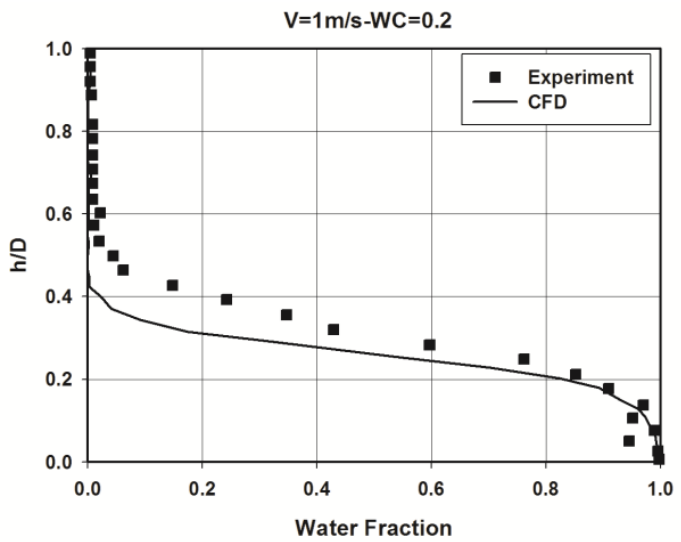

(a)

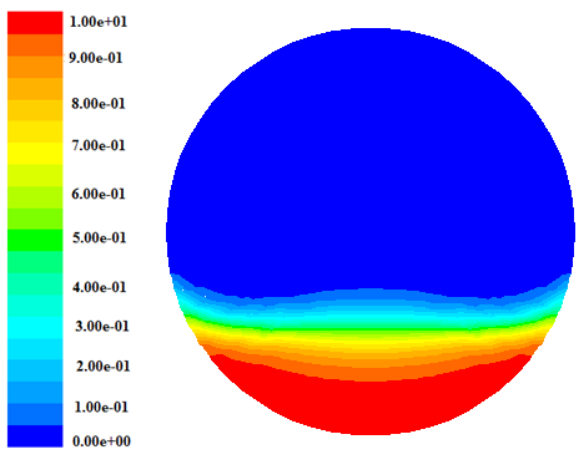

(b)

Fig. 5. Distribution of the water volume fraction across the pipe for an input water cut of $20 \%$ at a mixture velocity of $1 \mathrm{~m} / \mathrm{s}$. (a) Vertical distribution of the water fraction as predicted by the CFD model and obtained by measurement, (b) contours of the water volume fraction. 


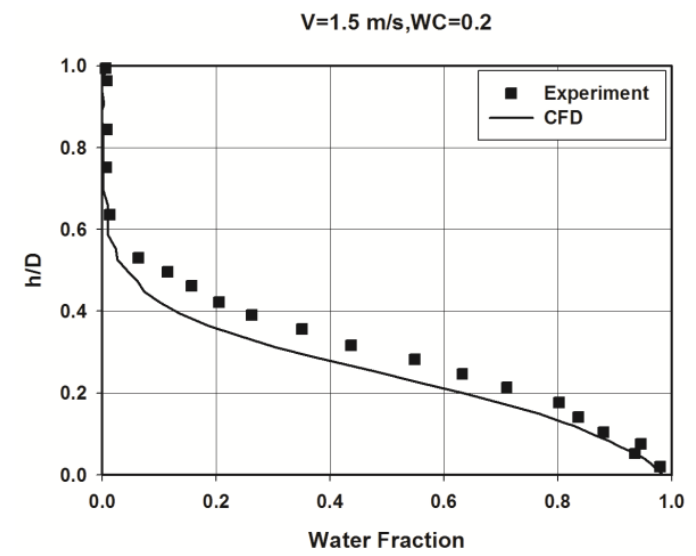

(a)
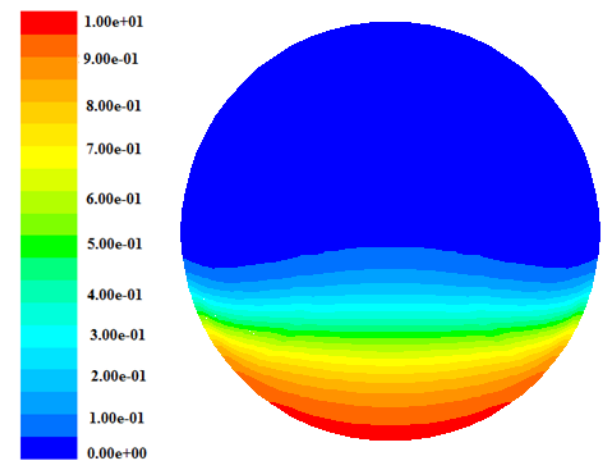

(b)

Fig. 6. Distribution of the water volume fraction across the pipe for an input water cut of $20 \%$ at a mixture velocity of $1 \mathrm{~m} / \mathrm{s}$. (a) Vertical distribution of the water fraction as predicted by the CFD model and obtained by measurement, (b) contours of the water volume fraction. 


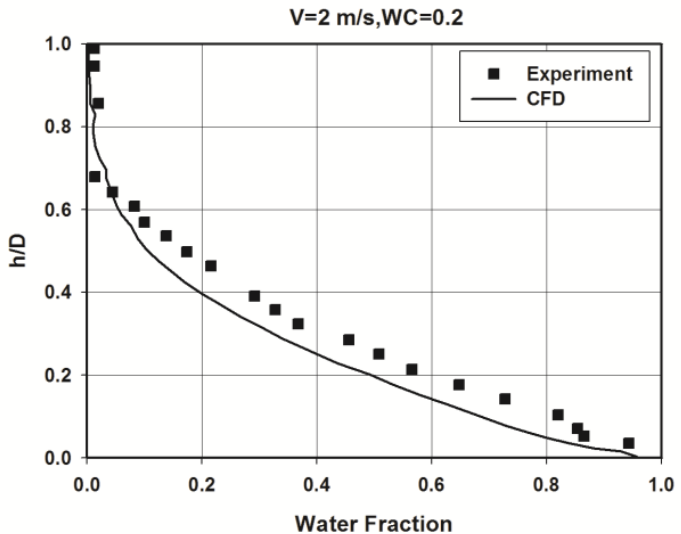

(a)

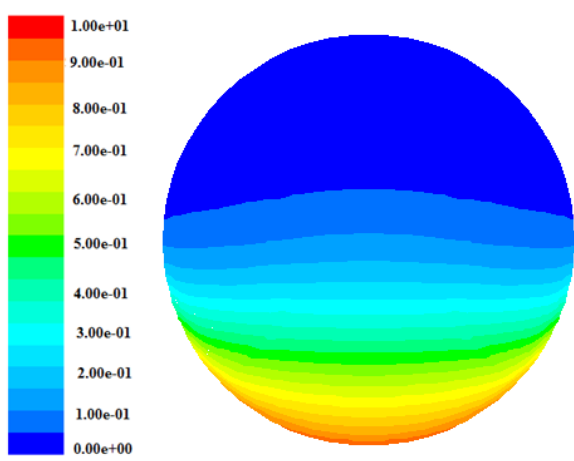

(b)

Fig. 7. Distribution of the water volume fraction across the pipe for an input water cut of $10 \%$ at a mixture velocity of $1 \mathrm{~m} / \mathrm{s}$. (a) Vertical distribution of the water fraction as predicted by the CFD model and obtained by measurement, (b) contours of the water volume fraction. 


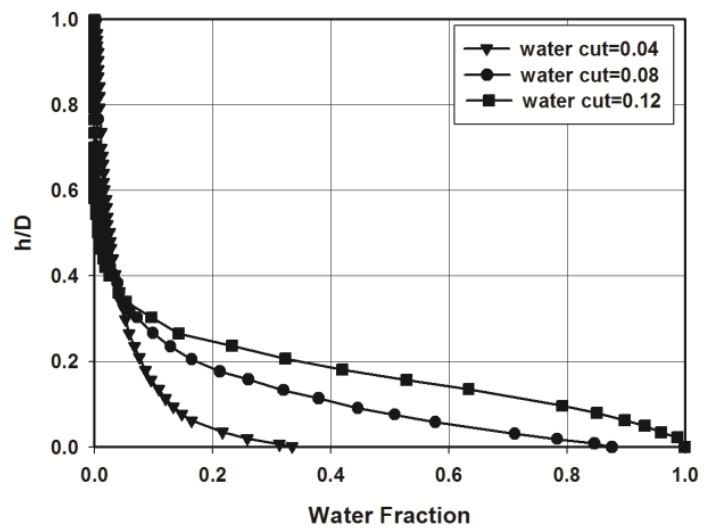

Fig. 8. The influence of water cut on the type of wetting for mixture velocity of $0.9 \mathrm{~m} / \mathrm{s}$. 


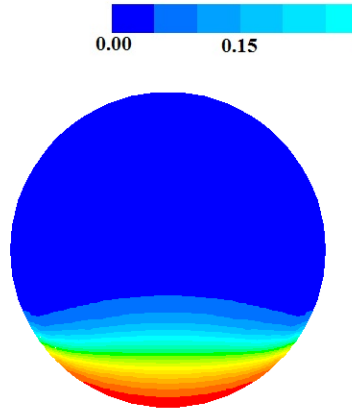

(a)

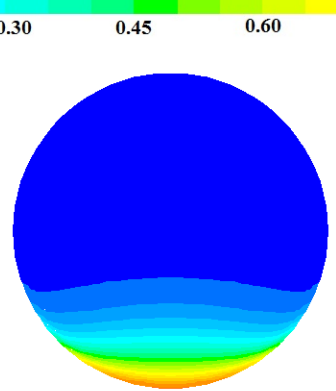

(b)

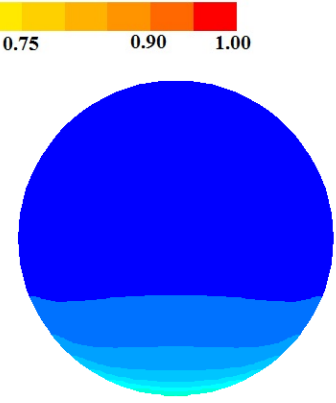

(c)

Fig. 9. Contours of water volume fraction as predicted by the CFD model for a mixture velocity of $0.9 \mathrm{~m} / \mathrm{s}$. (a) water cut=0.12, (b) water cut $=0.08$, (c) water cut $=0.04$ 
Table. $2 \mathrm{CO}_{2}$ corrosion rate and type of wetting for oil-water flow at different water cuts (Li, 2009; Tang et al., 2007).

\begin{tabular}{|c|c|c|c|}
\hline Mixture velocity (m/s) & Water cut (\%) & Phase wetting & Corrosion rate (mm/yr) \\
\hline 0.9 & 4 & Oil wetting & 0 \\
\hline 0.9 & 8 & Intermittent & 1.8 \\
\hline 0.9 & 12 & Water wetting & 3.9 \\
\hline
\end{tabular}




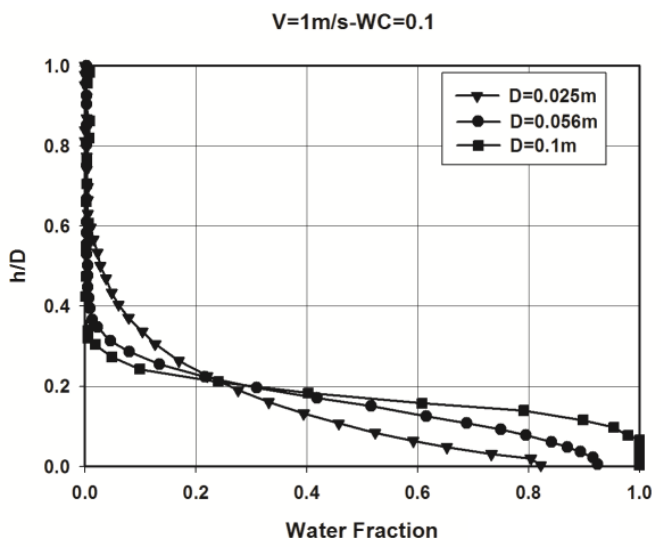

(a) $\mathrm{V}=1 \mathrm{~m} / \mathrm{s}, \mathrm{WC}=0.1$

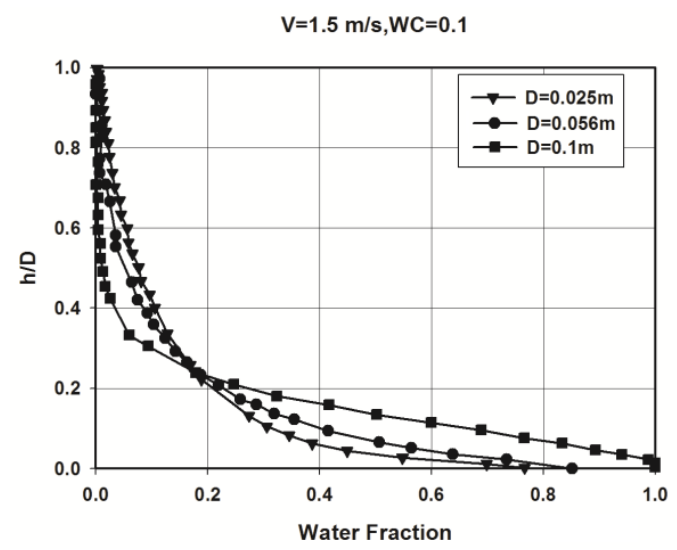

(b) $\mathrm{V}=1.5 \mathrm{~m} / \mathrm{s}, \mathrm{WC}=0.1$

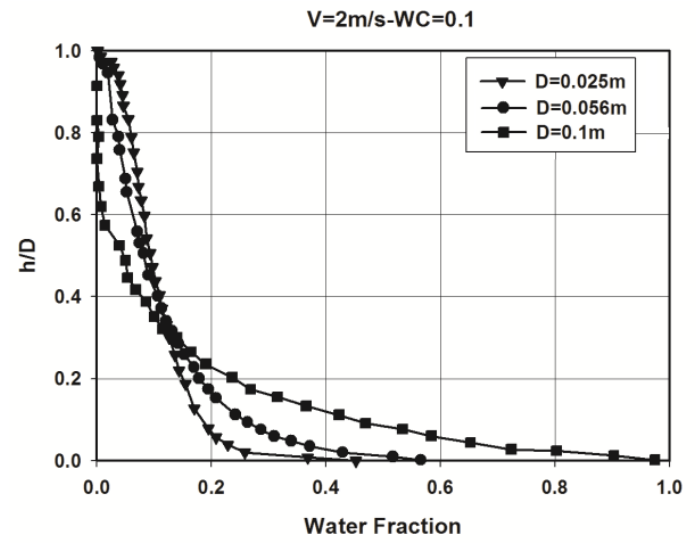

(c) $\mathrm{V}=2 \mathrm{~m} / \mathrm{s}, \mathrm{WC}=0.1$ 


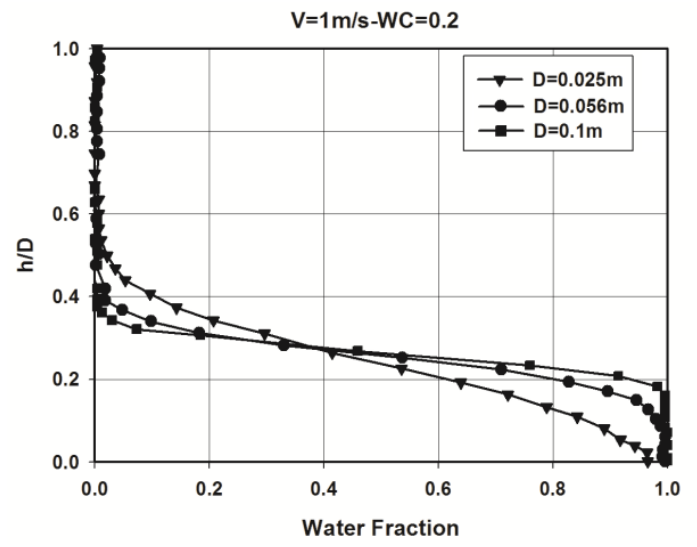

(d) $\mathrm{V}=1 \mathrm{~m} / \mathrm{s}, \mathrm{WC}=0.2$

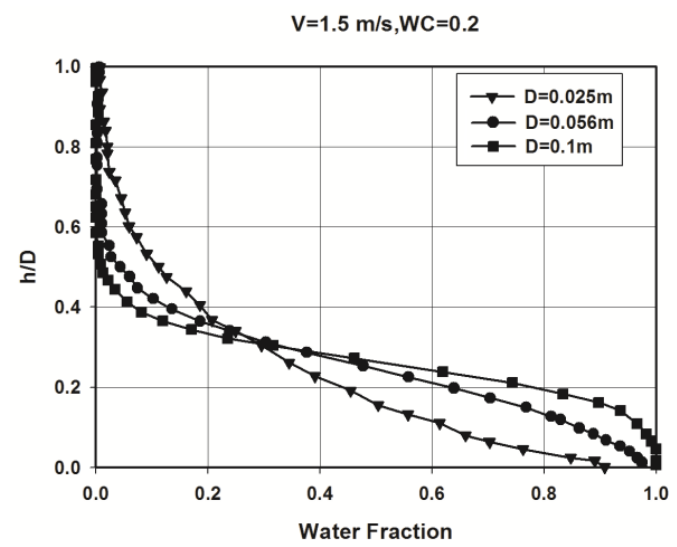

(e) $\mathrm{V}=1.5 \mathrm{~m} / \mathrm{s}, \mathrm{WC}=0.2$

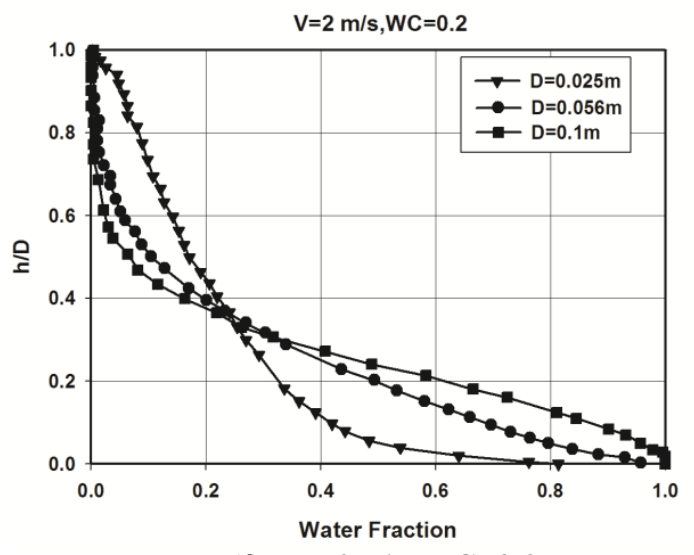

(f) $\mathrm{V}=2 \mathrm{~m} / \mathrm{s}, \mathrm{WC}=0.2$

Fig. 10. The influence of pipe diameter (D) on water entrainment. 


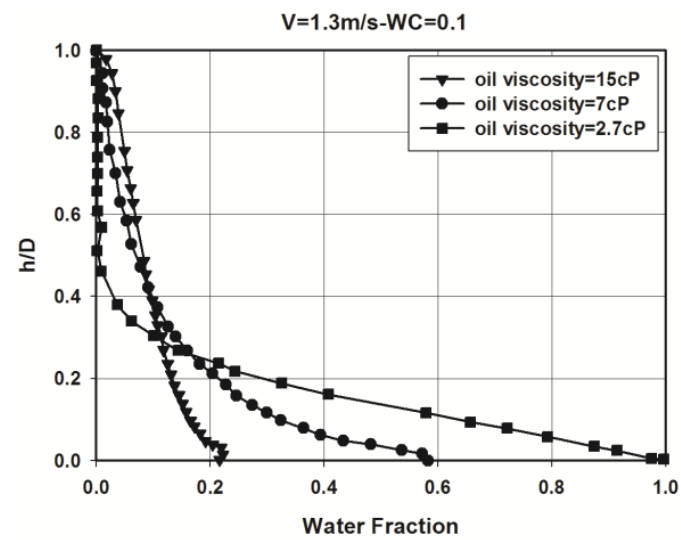

Fig. 11. The influence of oil viscosity on water entrainment (Pipe diameter=0.1m). 


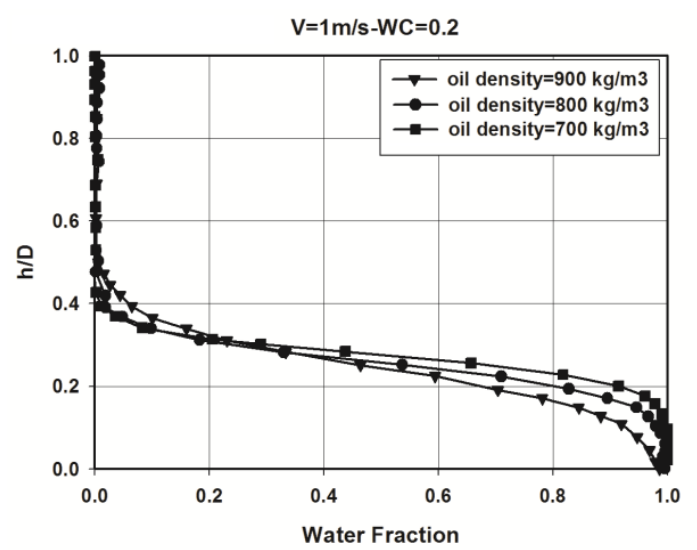

Fig. 12. The influence of oil density on water entrainment(Pipe diameter=0.056m) 


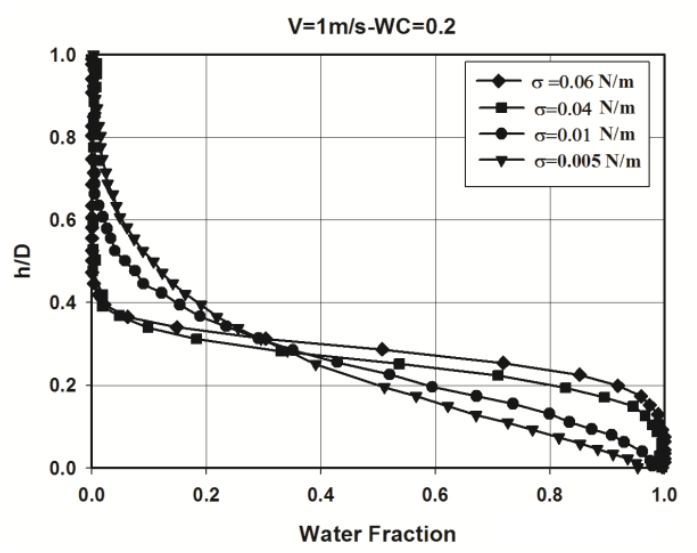

Fig. 13. The influence of interfacial tension on water entrainment(Pipe diameter $=0.056 \mathrm{~m})$ 


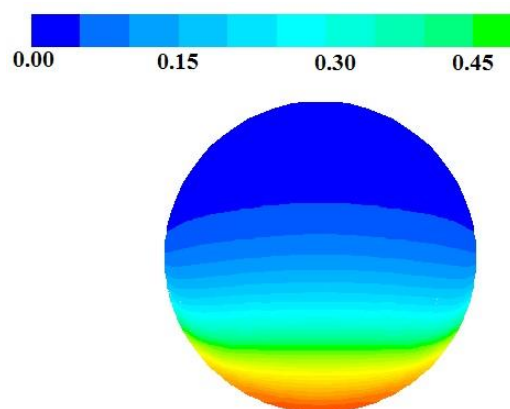

(a)

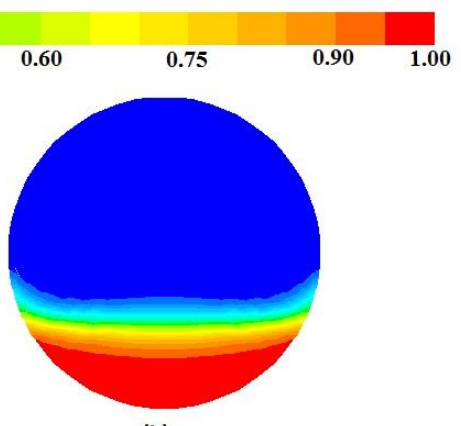

(b)

Fig.14. Contours of water volume fraction as predicted by the CFD model for an input water-cut of $20 \%$ and mixture velocity of $1 \mathrm{~m} / \mathrm{s}$. (a) oil-water interfacial tension $=0.005 \mathrm{~N} / \mathrm{m}$, (b) oil-water interfacial tension $=0.06 \mathrm{~N} / \mathrm{m}$ 